\title{
Identification of amino-acids in the $\alpha$-subunit first and third loops that are crucial for the heterospecific follicle-stimulating hormone activity of equid luteinizing hormone/choriogonadotropin
}

M Chopineau, N Martinat, J F Gibrat ${ }^{1}$, C Galet, F Lecompte, F Foulon-Gauze, C Pourchet, F Guillou an Y Combarnous

Physiologie de la Reproduction et des Comportements (PRC), UMR INRA-CNRS 6073, 37380 Nouzilly, France and ${ }^{1}$ Mathematique, Informatique et Genome, INRA, 78352 Jouy-en-Josas, France

(Correspondence should be addressed to M Chopineau; Email: chopinea@tours.inra.fr)

\begin{abstract}
Objective: To identify amino-acids in the $\alpha$-subunit important for expression of heterospecific FSH activity of horse (e) LH/choriogonadotropin (CG) (eLH) and donkey (dk) LH/CG (dkLH) (FSH/LH ratio ten times higher for eLH than for $\mathrm{dkLH}$ ); this FSH activity absolutely requires an equid (donkey or horse) $\alpha$-subunit combined with an equid $\beta$-LH subunit.

Design: Chimeric $\alpha$-subunits possessing the first 63 amino-acids of the porcine (p) and the last 33 amino-acids of the donkey $\alpha$-subunit $(\alpha \mathrm{p}$-dk) and the inverse $(\alpha \mathrm{dk}-\mathrm{p})$ were constructed. Porcinespecific amino-acids were introduced by mutagenesis in donkey $\alpha$-subunit at positions $70,85,89$, 93 and 96 ( $\alpha \mathrm{dk} 5 \mathrm{xmut}), 18\left(\alpha \mathrm{dk}^{\mathrm{K} 18 \mathrm{E}}\right)$ or $78\left(\alpha \mathrm{dk}^{\mathrm{I78A}}\right)$.

Methods: These different $\alpha$-subunits were co-transfected in COS-7 cells with $\beta$-eLH, $\beta$-dkLH and $\beta$-eFSH. The LH and FSH bioactivities of the dimers were then assessed in two heterologous in vitro bioassays. Results: $\alpha$-dk or $\alpha$ dk-p exhibited FSH activity when co-expressed with $\beta$-eLH but not with $\beta$-dkLH. $\alpha \mathrm{dk}^{\mathrm{K} 18 \mathrm{E}}$ or $\alpha \mathrm{dk}^{\mathrm{I78A}}$ gave hybrids with no FSH activity and important LH activity when expressed with $\beta$-dkLH. $\alpha \mathrm{dk}^{\mathrm{I7}}{ }_{\mathrm{A}} / \beta \mathrm{eLH}$ displayed an FSH/LH ratio as low as that of dkLH. However, mutation at 78 in $\alpha$-dk had no effect on FSH bioactivity when co-expressed with $\beta$-eFSH.

Conclusions: Amino-acids present in both the first two-thirds and the last third of the $\alpha$-subunit of equid LHs are involved in their heterologous biospecificity. Ile $\alpha 78$ exerts as strong an influence on it as the $\beta 102-103$ residues. By contrast, this residue plays no role in the FSH specificity of eFSH.
\end{abstract}

European Journal of Endocrinology 150 877-884

\section{Introduction}

The glycoprotein hormone family consists of luteinizing hormone (LH), follicle-stimulating hormone (FSH) and thyroid-stimulating hormone (TSH), which are secreted by the pituitary gland in all mammalian species, and choriogonadotropin (CG), which is secreted by the placenta in primates (hCG) and equids (eCG). These hormones are composed of a common $\alpha$-subunit and a hormone-specific $\beta$-subunit (1) which are non-covalently associated. Only the $\alpha-\beta$ dimer is capable of binding to receptors to induce biological responses. The tertiary structure of hCG $(2-4)$ and that of hFSH (5) show that both subunits have a similar topology: three of the disulfide bonds in each subunit form a cystin knot core that results in an elongated protein containing two paired loops at one end $(\alpha \mathrm{L} 1$ and $\alpha \mathrm{L} 3)$ and a single loop at the other $(\alpha \mathrm{L} 2)$.
LH and hCG recognize the same receptor (LHR) whereas FSH and TSH have their own cognate receptors. It is the $\beta$-subunit that determines the receptor binding specificity $(6,7)$. However, photoaffinity labeling $(8,9)$, immunological studies (10) and mutational studies $(11-13)$ demonstrated that the $\alpha$-subunit also interacts with the receptor.

In order to study more precisely which amino-acids of the $\alpha$-subunit are implicated in the interaction with gonadotropin receptors, we chose to work with the horse/donkey LH/CG model. Horse LH (eLH) and horse CG (eCG), which are identical apart from their oligosaccharide structures (they are encoded by the same gene (14)) are basically LH molecules in the horse but are unique in the family of gonadotropins as they exhibit both $\mathrm{LH}$ and FSH activities in species other than the horse (15). Donkey LH (dkLH) and donkey CG (dkCG) behave similarly but exhibit much 
less FSH activity than eLH and eCG $(16,17)$. Recombinant eLH/CG (eLH) and dkLH/CG (dkLH) expressed in COS-7 cells exhibit the same characteristics as the natural hormones: if the $\mathrm{FSH} / \mathrm{LH}$ ratio is set at 1 for eLH it is only 0.1 for dkLH (18).

We have previously shown that an equid $\alpha$-subunit is absolutely required for expression of FSH activity by equid LHs (19): a porcine $\alpha$-subunit is not able to confer any in vitro FSH activity to a hybrid with a donkey $\beta$-LH subunit whereas it permits full LH activity. The hybrid between the porcine $\alpha$-subunit and eLH $\beta$-subunit was very poorly active concerning its $\mathrm{LH}$ activity and showed no detectable FSH activity, suggesting that an equid $\alpha$-subunit is absolutely required for expression of both the LH and FSH activities of eLH.

In order to locate the determinants in the $\alpha$-subunit necessary to express heterologous FSH activity in equid LHs, we first expressed recombinant hybrids between the donkey or the horse LH $\beta$-subunit and chimeric $\alpha$-subunits composed of part of the porcine and part of the donkey $\alpha$-subunit, or mutated donkey $\alpha$-subunit containing specific porcine amino-acids. Secondly, to investigate the relationships between specific $\alpha$-subunit amino-acids and amino-acids known to influence FSH activity in the $\beta$-subunit (20), the $\alpha$-mutants were coexpressed with $\beta$-eLH ${ }^{\mathrm{V} 102 \mathrm{G}}{ }_{\mathrm{F} 103 \mathrm{P}}$ and $\beta$-dkLH ${ }^{\mathrm{G} 102 \mathrm{~V}}$ P103F. Thirdly, the most interesting $\alpha$-subunit mutant was co-expressed with $\beta$-eFSH in order to see whether the role of this amino-acid was similar for the expression of activity of eFSH itself. These mutant hormones were then tested for their in vitro LH and FSH bioactivities in heterologous bioassays.

\section{Materials and methods}

\section{Chimeric porcine-donkey $\alpha$-subunits}

The donkey and porcine $\alpha$-subunits cDNAs $(18,21)$ were excised from pBluescript vectors (Stratagene, Cambridge, Cambs, UK) via their Xba1 restriction sites, cut with the common $\mathrm{Xcm} 1$ restriction site (restriction site situated between amino acids 63 and 64 in the peptide sequence) and religated in a crossmanner, that is to say the beginning of the porcine subunit and the end of donkey subunit and the inverse (Table 1). After ligation of the chimeric $\alpha$-subunits in the cloning vector via Xba1, each chimeric cDNA construct was sequenced in both directions by the dideoxy chain termination method. Each cDNA was then subcloned into the eukaryotic expression vector pCDM8 (Invitrogen, Leek, Staffs, UK). The constructs were then amplified in MC1061/P3 (Invitrogen), purified using the Qiagen maxiprep plasmid kit (Coger, Paris, France) and the sequence was checked again.

\section{Mutant donkey $\alpha$-subunits}

Specific base substitutions were introduced in the donkey $\alpha$-subunit cDNA by extension of mutagenic oligonucleotides containing the desired mutations by using a site-directed mutagenesis kit (Quick-change Site-directed Mutagenesis kit, Stratagene).

Donkey $\alpha$-mutants were constructed in order to introduce, at specific positions, amino-acids present in the porcine $\alpha$-subunit (Table 1): $\alpha \mathrm{dk} 5$ xmut changing five positions in the donkey $\alpha$-subunit $(70,85,87,93$ and 96), $\alpha \mathrm{dk}^{\mathrm{K} 18 \mathrm{E}}$ changing lysine into glutamic acid at position 18 and $\alpha \mathrm{dk}^{178 \mathrm{~A}}$ changing isoleucine into alanine at position 78 . Each construct was sequenced in both directions by the dideoxy chain termination method to ensure that correct mutations were introduced. Each cDNA was then subcloned into the eukaryotic expression vector pCDM8 (Invitrogen). The constructs were then amplified in MC1061/P3 (Invitrogen), purified using the Qiagen maxiprep plasmid kit (Coger) and the sequence was checked again.

\section{$\beta$-subunits}

Donkey LH $\beta$-cDNA and horse LH $\beta$-cDNA in pCDM8 were used as well as mutant $\beta \mathrm{eLH}^{\mathrm{V} 102 \mathrm{G}}$ F103P and

Table 1 Amino-acid sequences of the donkey $\alpha$-subunit aligned with those of the horse, pig and human: only amino-acids in the horse, pig and human that differ from the donkey are indicated. Position of the $\mathrm{Xcml}$ restriction site is indicated by the arrow. Positions of the amino-acids mutated in the donkey $\alpha$-subunit are indicated in bold.

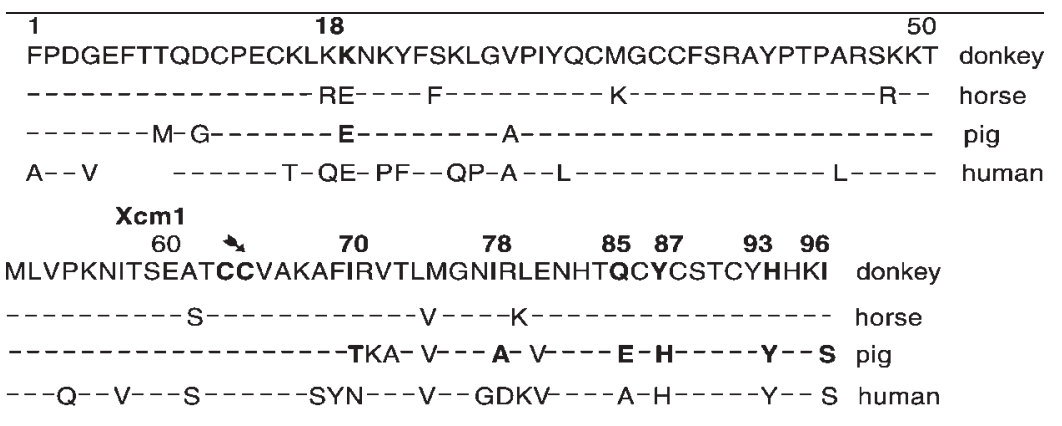

The different chimeric and mutant $\alpha$-subunits are: $\alpha p-d k: p(1-63)-d k(64-96) ; \alpha d k-p: d k(1-64)-$

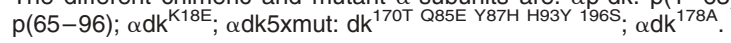


$\beta d \mathrm{kLH}^{\mathrm{G} 102 \mathrm{~V} \text { P103F }} \mathrm{cDNAs}(20)$. Horse FSH $\beta$-cDNA was cloned by RT-PCR in the laboratory from a horse pituitary with $3^{\prime}$ Race PCR and a specific $5^{\prime}$ primer. The sequence was found to be identical to the one recently published (22). This FSH $\beta$-cDNA was inserted into pCDM8.

\section{Transient transfections of COS-7 cells}

COS-7 monkey kidney cells (ATCC-CRL 1651), maintained at $37{ }^{\circ} \mathrm{C}$ under $5 \% \mathrm{CO}_{2}$ in a humidified atmosphere in Dulbecco's modified Eagle's medium (DMEM) supplemented with $10 \%$ fetal calf serum, were co-transfected at $65 \%$ confluency in $6 \mathrm{~cm}$ diameter Petri dishes with $2 \mu \mathrm{g}$ of each vector, one containing the $\alpha$-subunit (wild-type (wt), chimeric or mutant) and the other the $\beta$-subunit (donkey or horse or mutant 102-103), using calcium phosphate precipitation (18). Co-transfection of vectors containing $\alpha \mathrm{dk}^{\mathrm{I} 78 \mathrm{~A}} \mathrm{CDNA}$ and eFSH $\beta$ cDNA was also performed as well as $\alpha \mathrm{dk}$ and eFSH $\beta$. Control cells were transfected with the expression vector containing no insert. After $48 \mathrm{~h}$ incubation in serum-free DMEM, the media were harvested, centrifuged at $200 \mathrm{~g}$ for $10 \mathrm{~min}$ and the supernatants were stored at $-20^{\circ} \mathrm{C}$ until assayed.

\section{Estimations of bioactivities}

Bioactivities of secreted LH dimers were tested at different dilutions without previous estimation of concentration by immunoassays for the following reason: the anti-eLH antibodies which we have are highly specific for the equid LHs, they do not cross-react with porcine $\mathrm{LH}$, and as the mutations we introduce are amino-acids present in the porcine $\alpha$-subunit, we could not be sure that the hybrid and/or mutated molecules were equipotent in these assays. However, we have previously shown that initial quantification of the hybrid hormones is not a critical point, and that the LH activity can be taken as a measure of the quantity of biologically expressed active hormone present (19). In any case, we were essentially interested in $\mathrm{FSH} / \mathrm{LH}$ ratios which are independent of quantities.

Concerning the dimers obtained with the eFSH $\beta$-subunit $\left(\alpha \mathrm{dk} / \beta \mathrm{eFSH}\right.$ and $\left.\alpha \mathrm{dk}^{\mathrm{I} 78 \mathrm{~A}} / \beta \mathrm{eFSH}\right)$, which display no LH activity, it was necessary to quantify hormones. To measure the quantities of dimers obtained with $\alpha$-subunits co-transfected with the FSH $\beta$-subunit, we performed a displacement ELISA using a rabbit antieFSH antibody produced in the laboratory (number 803) and a standard eFSH (eFSH1368 purified in the laboratory: 6xeFSHA). As this antibody shows a $15 \%$ cross-reaction with dissociated eFSH, to confirm the equivalent concentrations obtained for the two samples we used another displacement ELISA with a rabbit antipFSH antibody produced in the laboratory number 513) which cross-reacts with eFSH but not with dissociated subunits.
The LH bioactivities of the recombinant hormones were estimated by measuring their abilities to stimulate testosterone production in a rat Leydig cell bioassay (23), and the FSH bioactivities were assessed in an in vitro progesterone stimulation assay using a Y1 cell line stably expressing the human FSH receptor (18). For each transfection, the dilutions of the media containing the $\alpha \mathrm{dk} / \beta \mathrm{eLH}$ hybrid giving $50 \%$ of the maximum of the biological response were normalized to $100 \%$ in both assays. As this hybrid (as well as the $\alpha \mathrm{dk} / \beta \mathrm{dkLH}$ hybrid) can be quantified with a sandwich ELISA (18), these dilutions corresponded to an $\mathrm{EC}_{50}$ of $28 \pm 6.9 \mathrm{ng} / \mathrm{ml}$ for the LH bioassay, and of $46.7 \pm 16 \mathrm{ng} / \mathrm{ml}$ for the FSH bioassay. The activities of the other recombinant hormones were calculated according to the dilution of the media giving $50 \%$ of the maximum of the biological response compared with the reference value. For expression with $\beta \mathrm{dkLH}$, it was the dilution of the media containing the $\alpha \mathrm{dk} / \beta \mathrm{dkLH}$ hybrid which was the reference $(100 \%$ for LH activity and $10 \%$ for FSH activity. These dilutions corresponded to an $\mathrm{EC}_{50}$ of $14.8 \pm 9.8 \mathrm{ng} / \mathrm{ml}$ for the LH bioassay and of $147.8 \mathrm{ng} / \mathrm{ml}$ for the FSH bioassay. Differences of quantities expressed between different transfections (number of COS-7 passages) are cleared as in each transfection experiment there was a reference dimer. So the percentage activity of a chimeric or mutant hybrid represents the sum of the intrinsic dimer activity and the intrinsic expression level (typically between 100 and $250 \mathrm{ng} / \mathrm{ml} \alpha \mathrm{dk} / \beta \mathrm{eLH}$ or $\alpha \mathrm{dk} / \beta \mathrm{dkLH})$.

\section{Molecular modelling}

To help visualize the positions of the amino-acids studied, models of $\alpha \mathrm{dk} / \beta \mathrm{eLH}$ and $\alpha \mathrm{dk} / \beta \mathrm{eFSH}$ were constructed with the program Modeller (salilab.org/modeller/modeller.html) (24) on the basis of hCG and hFSH three-dimensional structures $(3,5)$ respectively.

\section{Results}

\section{Bioactivities of chimeric porcine-donkey $\alpha$-subunits co-expressed with horse and donkey $L H \beta$-subunits}

The FSH/LH ratio was set at one for $\alpha \mathrm{dk} / \beta \mathrm{eLH}$. The hybrid $\alpha \mathrm{p} / \beta \mathrm{eLH}$ had an FSH/LH ratio of 0 as it exhibited no detectable FSH activity together with a very low LH activity (around 10\% LH activity). $\alpha$ p-dk or $\alpha \mathrm{dk}-\mathrm{p}$ mutant co-expressed with $\beta$-eLH permitted the appearance of some FSH activity (Table 2), but it was always lower than the FSH activity of $\alpha \mathrm{dk} / \beta \mathrm{eLH}$. These results showed that some FSH biodeterminants are present in two discontinuous domains of the donkey $\alpha$-subunit.

$\alpha \mathrm{p}-\mathrm{dk}$ co-expressed with $\beta \mathrm{dkLH}$ displayed full $\mathrm{LH}$ activity whereas no FSH activity could be detected 
Table 2 The FSH and $\mathrm{LH}$ activities and the calculated $\mathrm{FSH} / \mathrm{LH}$ ratios of recombinant-derived gonadotropins resulting from the co-transfection of $\beta$ eLH or $\beta \mathrm{dkLH}$ with different $\alpha$-porcine/donkey or $\alpha$-donkey mutants.

\begin{tabular}{|c|c|c|c|c|c|c|}
\hline \multirow[b]{3}{*}{$\alpha$-subunit } & \multicolumn{6}{|c|}{$\beta$-subunit } \\
\hline & \multicolumn{3}{|c|}{$\beta e L H$} & \multicolumn{3}{|c|}{$\beta d k L H$} \\
\hline & FSH activity & LH activity & $\mathrm{FSH} / \mathrm{LH}$ & FSH activity & LH activity & $\mathrm{FSH} / \mathrm{LH}$ \\
\hline$\alpha \mathrm{dk}$ & 100 & 100 & 1 & 10 & 100 & 0.1 \\
\hline$\alpha p$ & 0 & $<10$ & $0(n=5)$ & 0 & $105 \pm 47$ & $0(n=2)$ \\
\hline$\alpha p-d k$ & $7 \pm 5$ & $31 \pm 12$ & $0.21 \pm 0.11(n=5)$ & 0 & $67 \pm 40$ & $0(n=3)$ \\
\hline$\alpha \mathrm{dk}-\mathrm{p}$ & $8 \pm 4$ & $45 \pm 10$ & $0.16 \pm 0.10(n=5)$ & 0 & $107 \pm 42$ & $0(n=3)$ \\
\hline$\alpha \mathrm{dk}^{\mathrm{K} 18 \mathrm{E}}$ & $29 \pm 14.5$ & $52.5 \pm 15$ & $0.53 \pm 0.14(n=4)$ & 0 & $137 \pm 32$ & $0(n=3)$ \\
\hline$\alpha \mathrm{dk5xmut}$ & $265 \pm 191$ & $160 \pm 85$ & $1.56 \pm 0.40(n=2)$ & $24 \pm 13$ & $160 \pm 99$ & $0.15 \pm 0.02(n=2)$ \\
\hline$\alpha \mathrm{dk}^{178 \mathrm{~A}}$ & $8 \pm 2.1$ & $69 \pm 32$ & $0.14 \pm 0.07(n=4)$ & 0 & $95 \pm 35$ & $0(n=2)$ \\
\hline
\end{tabular}

With $\beta \mathrm{eLH}$, each hybrid was measured according to the dilutions of the harvested medium; the dilution of $\alpha \mathrm{dk} / \beta \mathrm{eLH}$ giving half the maximum of the response was normalized to $100 \%$ in LH dilution corresponding to $28 \pm 6.9 \mathrm{ng} / \mathrm{ml}$ ) and $\mathrm{FSH}$ (dilution corresponding to $46.7 \pm 16 \mathrm{ng} / \mathrm{ml}$ ) bioassays, the activities of the other recombinant hormones were calculated according to their dilution giving half the maximum of the response compared with that of $\alpha \mathrm{dk} / \beta \mathrm{eLH}$, and $\mathrm{FSH} / \mathrm{LH}$ ratios were then calculated.

With $\beta \mathrm{dkLH}$, each hybrid was measured according to dilutions of the harvested medium and $\alpha \mathrm{dk} / \beta \mathrm{LH}$ was given a reference activity of $100 \%$ in the $\mathrm{LH}$ assay (dilution corresponding to $14.8 \pm 9.8 \mathrm{ng} / \mathrm{ml}$ ) and $10 \%$ in the $\mathrm{FSH}$ assay (dilution corresponding to $147.8 \pm 12.6 \mathrm{ng} / \mathrm{ml}$ ). The activities of the other recombinant hormones were calculated according to their dilution giving $50 \%$ of the response compared with that of $\alpha \mathrm{dk} / \beta \mathrm{dkLH}$, and $\mathrm{FSH} / \mathrm{LH}$ ratios were then calculated. $\alpha \mathrm{dk} / \beta \mathrm{eLH}$ and $\alpha \mathrm{dk} / \beta \mathrm{dkLH}$ were typically produced at between 100 and $250 \mathrm{ng} / \mathrm{ml}$ in COS-7 media. An activity of 0 means that it was undetectable under the assay conditions (the limit of detection being $5 \mathrm{ng} / \mathrm{ml} \alpha \mathrm{dk} / \beta \mathrm{eLH}$ in each assay).

(Table 2). Similar results were obtained with $\alpha \mathrm{dk}-\mathrm{p}$ coexpressed with $\beta$ dkLH, showing that the integrity of the $\alpha$-subunit is needed for FSH activity of donkey LH. Figure 1 illustrates this difference in activity.

\section{Bioactivities of mutant $\alpha$-subunits coexpressed with horse and donkey LH $\beta$-subunits}

$\alpha \mathrm{dk}^{\mathrm{K} 18 \mathrm{E}}$ co-expressed with the horse LH $\beta$-subunit gave a hybrid with an $\mathrm{FSH} / \mathrm{LH}$ ratio diminished by a factor of

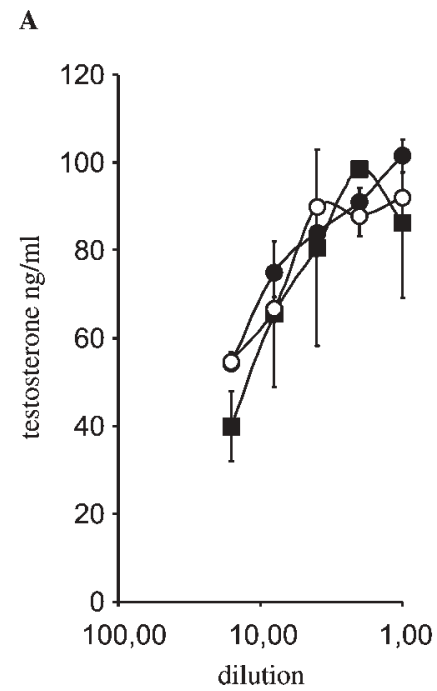

2 (Table 2). Contrary to what was observed with eLH $\beta$-subunit, $\alpha \mathrm{dk}^{\mathrm{K} 18 \mathrm{E}}$ co-expressed with dkLH $\beta$-subunit gave a hormone with no FSH activity (Table 2 ) (although it exhibited full LH activity compared with $\alpha \mathrm{dk} / \beta \mathrm{dkLH})$.

Co-expression of the $\alpha \mathrm{dk} 5$ xmut with eLH $\beta$-subunit gave a hybrid with an identical $\mathrm{FSH} / \mathrm{LH}$ ratio (Table 2). As with eLH $\beta, \alpha \mathrm{dk} 5 \mathrm{xmut}$ co-expressed with dkLH $\beta$ did not change the FSH/LH ratio (Table 2). Mono mutation at position $85,87,89$, or 96 gave identical results (data not shown).

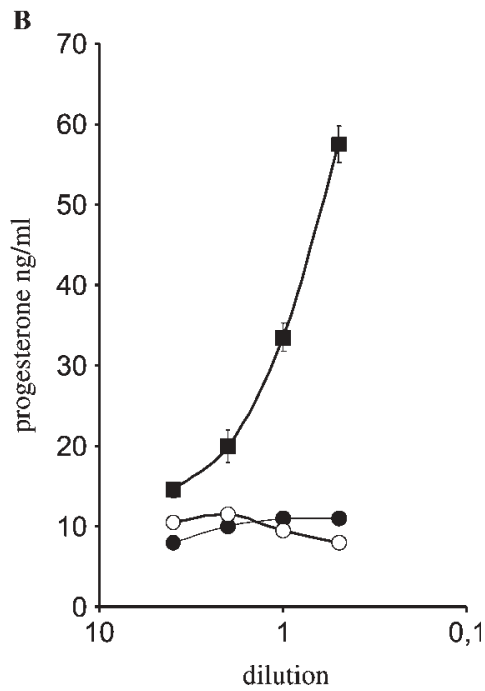

Figure 1 (A) Bioassay of LH activity of chimeric porcine-donkey $\alpha$-subunits co-expressed with donkey LH $\beta$-subunit. The media from transfected COS-7 cells were incubated for $4 \mathrm{~h}$ at $34^{\circ} \mathrm{C}$ with rat Leydig cells. Supernatants were then harvested and testosterone was assayed with a specific RIA. (B) Bioassay of FSH activity of chimeric porcine-donkey $\alpha$-subunits co-expressed with donkey LH $\beta$-subunit. Y1 cells stably transfected with the human FSH receptor were incubated for $4 \mathrm{~h}$ with the test samples and supernatants were harvested and assayed for progesterone with a specific RIA. Samples of media of the different constructs $\alpha \mathrm{dk} / \beta \mathrm{dkLH}(\mathbf{\square}), \alpha \mathrm{p}-\mathrm{dk} / \beta \mathrm{dkLH}$ $(\bullet)$ and $\alpha \mathrm{dk}-\mathrm{p} / \beta \mathrm{dkLH}(O)$ were tested at different dilutions. The first dilution point in the FSH bioassay is media concentrated twofold (dilution 0.5). Each point is the mean \pm S.E.M. of duplicate measurements from one representative experiment from three different transfections. 
A

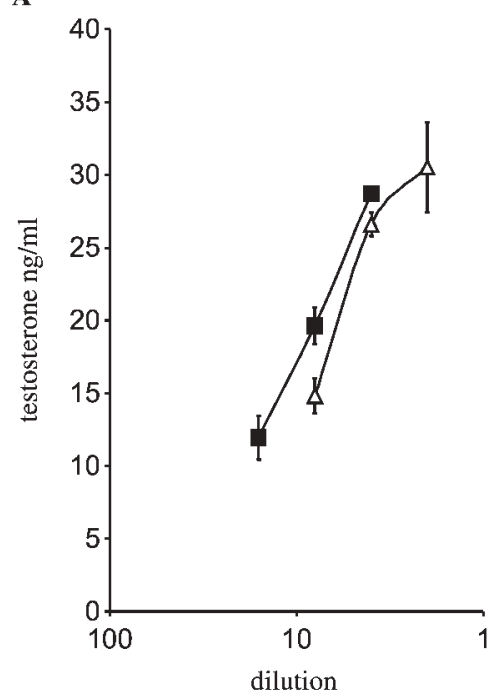

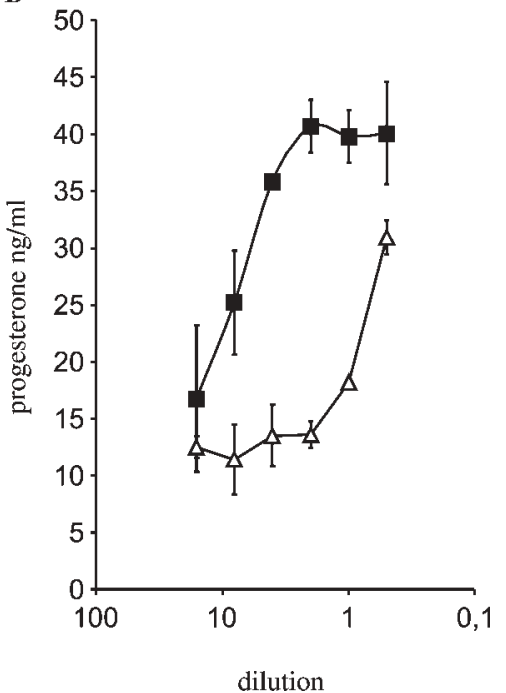

Figure 2 (A) Bioassay of LH activity of $\alpha \mathrm{dk} \beta \mathrm{eLH}$ and $\alpha \mathrm{dk}^{178 \mathrm{~A}} \beta \mathrm{eLH}$. The media from transfected COS-7 cells were incubated for $4 \mathrm{~h}$ at $34^{\circ} \mathrm{C}$ with rat Leydig cells. Supernatants were then harvested and testosterone was assayed with a specific RIA. (B) Bioassay of FSH activity of $\alpha \mathrm{dk} \beta \mathrm{eLH}$ and $\alpha \mathrm{dk}^{178 \mathrm{~A}} \beta \mathrm{eLH}$. Y1 cells stably transfected with the human FSH receptor were incubated for $4 \mathrm{~h}$ with the test samples, and supernatants were harvested and assayed for progesterone with a specific RIA. Samples of media of the constructs $\alpha \mathrm{dk} / \beta \mathrm{eLH}(\square)$ and $\alpha \mathrm{dk}^{178 \mathrm{~A}} \beta \mathrm{eLH}(\triangle)$ were tested at different dilutions. The first dilution point in the FSH bioassay is media concentrated twofold (dilution 0.5). Each point is the mean \pm S.E.M. of duplicate measurements from one representative experiment from four different transfections.

$\alpha \mathrm{dk}^{\mathrm{I} 78 \mathrm{~A}}$ co-expressed with eLH $\beta$-subunit gave a hybrid hormone displaying an $\mathrm{FSH} / \mathrm{LH}$ ratio which was decreased tenfold $(\mathrm{FSH} / \mathrm{LH}=0.14)$ with an LH activity of $69 \%$ compared with $100 \%$ for $\alpha \mathrm{dk} / \beta \mathrm{eLH}$ (Table 2 and Fig. 2); when co-expressed with dkLH $\beta$-subunit it gave a hybrid hormone displaying full LH activity without FSH activity (Table 2).

Molecular modelling shows that amino-acids 18 and 78 of the donkey $\alpha$-subunit are close together in the three-dimensional structure (Fig. 3); amino-acid 18 belongs to $\alpha \mathrm{L} 1$ whereas amino-acid 78 belongs to $\alpha \mathrm{L} 3$.

\section{Bioactivities of donkey $\alpha$-subunit mutated in position 18 or 78 coexpressed with $\beta e L H^{V 102 G}$ F103P or BdkLHG102V Pfo3F}

Co-expression of either of the two mutant donkey $\alpha$-subunits with $\beta \mathrm{dkLH}^{\mathrm{G} 102 \mathrm{~V}} \mathrm{P} 103 \mathrm{~F}$ gave hybrids displaying a lowered $\mathrm{FSH} / \mathrm{LH}$ ratio (Table 3) compared with $\alpha \mathrm{dk} / \beta \mathrm{dkLH}{ }^{\mathrm{G} 102 \mathrm{~V} \text { P103F }}$ whereas mutants $\alpha \mathrm{dk}^{\mathrm{I78A}}$ or $\alpha \mathrm{dk}^{\mathrm{K} 18 \mathrm{E}}$ co-expressed with $\beta \mathrm{eLH}^{\mathrm{V} 102 \mathrm{G}} \mathrm{F} 103 \mathrm{P}$ gave dimers without FSH activity (Table 3).

\section{Bioactivities of donkey $\alpha$-subunit mutated in position 78 coexpressed with horse FSH $\beta$-subunit}

Estimation of the quantities of FSH dimer secreted was performed by ELISA, and FSH in vitro bioassay on human FSH receptor showed that $\alpha \mathrm{dk}^{\mathrm{I78A}}$ co-expressed with eFSH $\beta$ displayed an FSH activity similar to that of $\alpha \mathrm{dk} / \beta \mathrm{eFSH}$ (Fig. 4).

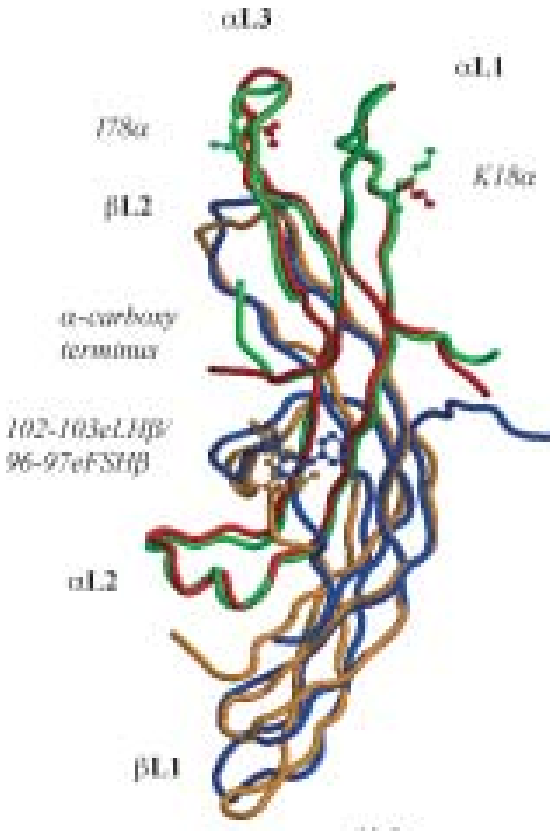

B.3

Figure 3 Model of $\alpha \mathrm{dk} / \beta \mathrm{BLH}$ superimposed with that of $\alpha \mathrm{dk} / \beta \mathrm{eFSH}$. Models have been constructed with the program Modeller (24) on the basis of the three-dimensional structure of hCG (3) and hFSH (5) respectively. ( $\alpha \mathrm{dk} / \beta \mathrm{eLH}$ : $\alpha \mathrm{dk}$ red, $\beta \mathrm{eLH}$ blue; $\alpha \mathrm{dk} / \beta \mathrm{eFSH}$ : $\alpha \mathrm{dk}$ green, $\beta \mathrm{eFSH}$, orange.) The images were obtained with Rasmol (www.umass.edu/microbio/rasmol). 


\section{Discussion}

As an equid $\alpha$-subunit is absolutely required for the heterospecific FSH activity of equid LHs (19), we first constructed chimeric porcine/donkey $\alpha$-subunits; the replacement of $\alpha \mathrm{p}$ by $\alpha \mathrm{p}-\mathrm{dk}$ or $\alpha \mathrm{dk}-\mathrm{p}$ conferred FSH activity to the hybrids formed with eLH $\beta$ but LH bioactivity was still low compared with that of $\alpha \mathrm{dk} / \beta \mathrm{eLH}$ (31 and $45 \%$ respectively). Whether this low $\mathrm{LH}$ activity is due to poor $\alpha / \beta$ eLH secretion or to misfolding of the dimer not permitting full interaction with the LH receptor is still to be determined. However, these results showed that some determinants present in loops $1+2$ and loop 3 of the donkey $\alpha$-subunit are able to confer some FSH activity to the secreted hybrid. By contrast, when these chimeric $\alpha$-subunits were expressed with donkey $\beta \mathrm{LH}$, the secreted hybrids did not display any FSH activity although high LH activity was observed.

Only four amino-acids differ between loops $1+2$ of porcine and donkey $\alpha$-subunits (Table 1). Among them, position 18 is occupied by a negatively charged amino-acid in the pig (Glu) and a positively charged amino-acid in the donkey (Lys). Co-expression of $\alpha \mathrm{dk}^{\mathrm{K} 18 \mathrm{E}}$ with $\beta \mathrm{eLH}$ gave a hybrid displaying an $\mathrm{FSH} / \mathrm{LH}$ ratio half that of $\alpha \mathrm{dk} / \beta \mathrm{eLH}$, whereas co-expression with $\beta$ dkLH gave a hybrid with its FSH activity abolished (whereas its LH activity was conserved). Thus Lys $^{18}$ is crucial for the expression of FSH activity of dkLH whereas it has less impact for the expression of FSH activity of eLH. It is noteworthy that the aminoacid present at position 18 in the horse $\alpha$-subunit is Glu as in the other non-equid $\alpha$-subunits. Thus for $\mathrm{eLH}$ and the hybrid $\alpha \mathrm{e} / \beta \mathrm{dkLH}$, the determinant implicated in the FSH activity has to be searched for elsewhere. It must be pointed out that these experiments have been performed using donkey and not horse $\alpha$-subunit. Horse $\alpha$-subunit displays some unique amino-acids ( $\operatorname{~rg}^{17}$ instead of Lys in all other species, $\mathrm{Phe}^{23}$ instead of $\mathrm{Ser}^{23}$ in all other species, Lys ${ }^{33}$ instead of $\mathrm{Met}^{33}$ in all other species) that might be implicated in the FSH expression of equid $\mathrm{LH}$ hybrids obtained with horse $\alpha$-subunit.

Lys $^{18}$ is located on $\alpha \mathrm{L} 1$ as shown in the model constructed on the basis of the three-dimensional structure of hCG (Fig. 3), and it points outside the molecule on its convex surface. It has been suggested that $\mathrm{Phe}^{22}$ in human $\alpha \mathrm{L} 1$ (the numbering of the human $\alpha$-subunit has been adjusted to the numbering of all $\alpha$-subunit species) may interact with the LH receptor, as replacement of this amino-acid by a hydrophilic residue (Thr) gave a hybrid hCG which was twice as active as hCG in the stimulation of progesterone $(25,26)$. The authors hypothesize that this replacement probably results in weakening the interaction between the two subunits and that this short conformational change affects the receptor binding site probably located in close proximity to $\alpha \mathrm{Phe}^{22}$. However, implication of $\alpha \mathrm{L} 1$ in direct interaction with the LH receptor is controversial as an immunological study showed that the surface of hCG $\alpha \mathrm{L} 1$ furthest from the $\beta$-subunit interface can be recognized by a monoclonal antibody when hCG is bound to the LH receptor (27). The data in the literature only concern hLH or hCG and their interaction with the LH receptor; no effect of mutations on $\alpha \mathrm{L} 1$ has been reported for the interaction of FSH hormone and its receptor. Epitope mapping studies of alpha FSH show that this region is not accessible for neutralizing anti-alpha antibodies (28).

In the 33 positions after the Xcm 1 site of the $\alpha$-subunit, we were first interested in five amino-acids that differ between pig and equid $\alpha$-subunits: positions 70, 85, 89, 93 and 96 (Table 1). We first focused on this C-terminal part of the $\alpha$-subunit as deletion and mutagenesis studies had previously shown that this region in the human $\alpha$-subunit was important for binding and bioactivity of gonadotropins (11-13, 29-31). Moreover, hCG with its $\alpha$-subunit elongated by 24 residues beyond the terminal serine displayed full receptor binding and a sixfold reduction in $\mathrm{LH}$ bioactivity assessed on rat Leydig cells (32). However, this study shows that the mutations introduced in the C-terminal part of $\alpha$-dk did not abolish FSH activity of dkLH or eLH, showing that these unique positions in the equid $\alpha$-subunits do not favor interaction with the FSH receptor.

We were thus interested in other amino-acids which differ in donkey and pig $\alpha$-subunits in the 33 positions after the Xcm 1 site (loop $3+$ C-terminal): $\alpha \mathrm{dk}^{\text {Ile78Ala }}$ abolished FSH activity of donkey LH whereas its LH activity remained unchanged. Moreover, $\alpha \mathrm{dk}^{\text {Ile78Ala }}$ co-transfected with $\beta \mathrm{eLH}$ gave a hybrid with a lowered FSH/LH ratio (0.14 versus 1 for $\alpha \mathrm{dk} / \beta \mathrm{eLH})$ showing that Ile with its large hydrophobic side chain plays an important role in the interaction with the FSH receptor. This amino-acid is situated on $\alpha \mathrm{L} 3$ and points inside the molecule (Fig. 3). The amino-acid present in the human $\alpha$-subunit in position 78 is Phe; when it was

Table $3 \mathrm{FSH} / \mathrm{LH}$ ratios of mutants $\alpha \mathrm{dk}^{\mathrm{K} 18 \mathrm{E}}$ and $\alpha \mathrm{dk}^{178 \mathrm{~A}}$ co-expressed with $\beta \mathrm{e}^{\mathrm{V} 102 \mathrm{G}-\mathrm{F} 103 \mathrm{P}}$ and $\beta \mathrm{dk}^{\mathrm{G} 102 \mathrm{~V}-\mathrm{P} 103 \mathrm{~F}} \mathrm{LH}$ mutants.

\begin{tabular}{|c|c|c|c|c|c|}
\hline$\beta d k L H$ mutant & FSH/LH ratio & $n$ & $\beta$ eLH mutant & FSH/LH ratio & $n$ \\
\hline$\alpha d k \beta d k L H$ & 0.1 & & $\alpha \mathrm{dk} \beta \mathrm{eLH}$ & 1 & \\
\hline$\alpha d k \beta d k L H^{G 102 V-P 103 F}$ & $0.72 \pm 0.15$ & 4 & $\alpha d k \beta e L H^{\text {102G-F103P }}$ & $0.05 \pm 0.04$ & 3 \\
\hline$\alpha \mathrm{dk}^{\mathrm{k} 18 \mathrm{E}} \beta \mathrm{dkLH} \mathrm{G}^{\mathrm{G} 102 \mathrm{~V}-\mathrm{P} 103 \mathrm{~F}}$ & $0.24 \pm 0.08$ & 2 & $\alpha \mathrm{dk}^{\mathrm{K} 18 \mathrm{E}}{ }_{\beta \mathrm{eLH}} \mathrm{V}^{\mathrm{V} 102 \mathrm{G}-\mathrm{F} 103 \mathrm{P}}$ & $0.01 \pm 0.01$ & 3 \\
\hline$\alpha \mathrm{dk}^{178 \mathrm{~A}} \beta \mathrm{dkLH} \mathrm{H}^{\mathrm{G} 102 \mathrm{~V}-\mathrm{P} 103 \mathrm{~F}}$ & 0.1 & 1 & $\alpha \mathrm{dk}^{178 \mathrm{~A}} \beta \mathrm{BLH}^{\mathrm{V} 102 \mathrm{G}-\mathrm{F} 103 \mathrm{P}}$ & 0 & 2 \\
\hline
\end{tabular}




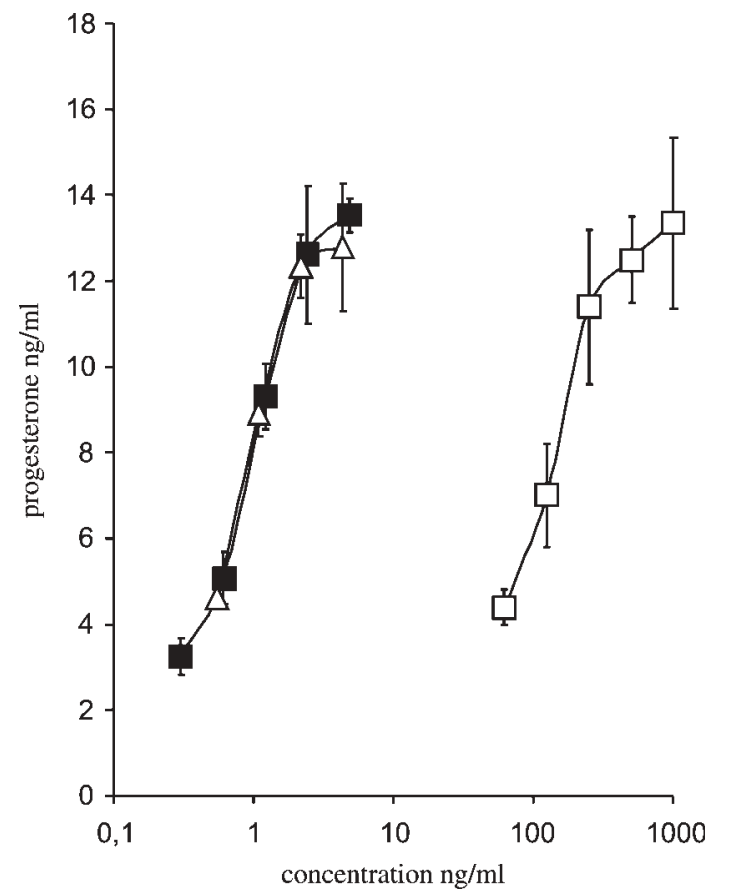

Figure 4 FSH bioactivity of $\alpha \mathrm{dk} / \beta \mathrm{eFSH}$ and $\alpha \mathrm{dk}^{178 \mathrm{~A}} / \beta \mathrm{eFSH}$. Y1 cells stably transfected with the human $\mathrm{FSH}$ receptor were incubated for $4 \mathrm{~h}$ with the test samples, and supernatants were harvested and assayed for progesterone with a specific RIA.

Samples of media of the different constructs $\alpha \mathrm{dk} / \beta \mathrm{eFSH}(\square)$ and $\alpha \mathrm{dk}^{178 \mathrm{~A}} / \beta \mathrm{eFSH}(\triangle)$ were tested at different concentrations previously estimated by ELISA. FSH bioactivity of eCG $652(\square)$ $(5000 \mathrm{iu} / \mathrm{mg})$ is shown for comparison. Each point is the mean \pm S.E.M. of duplicate measurements from one representative experiment from two different transfections.

mutated to Ala, FSH bioactivity on Y1 cells stably transfected with the human FSH receptor was the same as that of wtFSH (13).

Amino-acids in positions 18 and 78 which have been found to be important for FSH activity of equid LHs in this study are situated close together in the threedimensional structure but are located on opposite faces of the molecule (Fig. 3). They are located in an area which is part of a solvent-exposed hydrophobic patch in human FSH. This hydrophobic patch is formed by loops $\alpha \mathrm{L} 1$ (amino-acids 20-22), $\alpha \mathrm{L} 3$ (amino-acids 75 and 78) and $\beta \mathrm{L} 2$ and it has been proposed to play a role in receptor binding or signal transduction (5). Our results are thus in agreement with this hypothesis. Moreover, it has been suggested that the end of loops 1 and 3 of the $\alpha$-subunit of hCG would be in the vicinity of the extracellular loop 2 of the LH/CG receptor and could potentially transduce a signal (33).

Co-transfections of $\alpha \mathrm{dk}$ mutated at positions 18 or 78 with mutants in positions $102-103$ of the $\beta-\mathrm{LH}$ subunit were then performed as we have previously shown that the high heterologous FSH activity of eLH was due to the presence of Val Phe in 102-103 of the $\beta$-subunit (20). We observed an abolition of the weak FSH activity of the hybrids obtained with $\beta e L H^{\mathrm{V} 102 \mathrm{G}} \mathrm{F} 103 \mathrm{P}$ and $\alpha \mathrm{dk}$ mutated at positions 18 or 78 , and a large diminution of the FSH/LH ratio for the $\alpha$-mutants co-transfected with $\beta \mathrm{dkLH}^{\mathrm{G} 102 \mathrm{~V}} \mathrm{P} 103 \mathrm{~F}$, showing that the amino-acids present at 18 and 78 in the $\alpha$-subunit act in synergy with amino-acids present at 102-103 of the equid LH $\beta$-subunits to determine the level of FSH activity of equid LHs.

To summarize, the low heterospecific FSH activity of donkey LH requires Lys at position 18 together with Ile at position 78 in the $\alpha$-subunit, and some specific amino-acids to be present on the $\beta$ donkey sequence, $\mathrm{Met}^{45}$ being implicated - Met ${ }^{45}$ mutated in Leu ${ }^{45}$ present in all non-equid $\beta \mathrm{LH}$-subunits gave a hybrid after co-transfection with the $\alpha$-dk subunit which had no FSH activity (data not shown). The high FSH activity of horse $\mathrm{LH}$ is due to Val Phe at positions 102-103 in the $\beta$-subunit, in conjunction with $\mathrm{Ile}^{78}$ in the $\alpha$-subunit and probably other specific horse $\alpha$ amino-acids. How these specific determinants induce FSH bioactivity is still to be solved - do they directly contact the receptor and participate to the high affinity site or do they permit signal transduction once the high affinity binding to the receptor has been performed? The substitution with Ala at position 78 may enhance hydrophobic interactions with $\alpha \mathrm{L} 1$ residues constraining the distance between subunits or alternatively may modify interactions with the eLH $\beta$-subunit residue $\mathrm{Met}^{45}\left(\mathrm{Tyr}^{39}\right.$ in eFSH $\beta$ ), again affecting the final disposition of the two $\alpha$-subunit loops relative to one another.

In contrast, when $\alpha \mathrm{dk}^{\mathrm{I78A}}$ is co-expressed with horse FSH $\beta$-subunit, the dimer displayed the same FSH activity as the one containing wild-type $\alpha \mathrm{dk}$, showing that $\mathrm{Ile}^{78}$ is not crucial for interaction of eFSH with heterospecific FSH receptors. Nevertheless, it must be pointed out that eCG and eLH have a low FSH activity compared with eFSH and then only in heterologous species. Moreover, donkey LH has even lower FSH activity and zebra LH has none. Probably heterospecific FSH activity of equine LH/CG is due to some different structural features than those implicated in the FSH activity of genuine FSHs. The superimposition of the two models $\alpha \mathrm{dk} / \beta \mathrm{eLH}$ with $\alpha \mathrm{dk} / \beta \mathrm{eFSH}$ (Fig. 3) shows that the overall structures are very similar. However, it is clear from the present data that the common $\alpha$-subunit can influence the specificity of gonadotropins. Indeed, we were able to abolish the high heterospecific FSH activity of $\alpha \mathrm{dk} / \beta \mathrm{eLH}$ by changing only one amino-acid in loop 3 of the $\alpha \mathrm{dk}$ subunit. This is, in fact, as efficient as changing the $\beta-102-103$ sequence previously shown to play a prominent role in gonadotropin specificity.

\section{Acknowledgements}

The authors are grateful to A Ythier (Ares Serono, Geneva, Switzerland) for the gift of Y1 cells stably expressing the human FSH receptor, and to M Pelloile (INRA, Nouzilly, France) for sequencing the cDNAs. 
They also acknowledge the rat breeding staff (C Cahier, M Vignault and J C Braguer, INRA, Nouzilly, France) for technical assistance.

\section{References}

1 Pierce JG \& Parsons TF. Glycoprotein hormones: structure and function. Annual Review of Biochemistry 198150 465-495.

2 Lapthorn AJ, Harris DC, Littlejohn A, Lustbader JW, Canfield RE, Machin KJ, Morgan FJ \& Isaacs NW. Crystal structure of human chorionic gonadotrophin. Nature 1994369 455-461.

3 Wu H, Lustbader JW, Liu Y, Canfield RE \& Hendrickson WA. Structure of human chorionic gonadotrophin at 2.6A resolution from MAD analysis of the selenomethionyl protein. Structure 19942 545-558.

4 Tegoni M, Spinelli S, Verhoeyen M, Davis P \& Cambillau C. Crystal structure of a ternary complex between human chorionic gonadotropin (hCG) and two Fv fragments specific for the $\alpha$ - and $\beta$-subunits. Journal of Molecular Biology 1999289 1375-1385.

5 Fox KM, Dias JA \& Van Roey P. Three-dimensional structure of human follicle-stimulating hormone. Molecular Endocrinology $200115378-389$.

6 Combarnous Y. Molecular basis of the specificity of binding of glycoprotein hormones to their receptors. Endocrine Reviews 1992 13 670-691.

7 Moyle WR, Campbell RK, Myers RV, Bernard MP, Han Y \& Wang X. Co-evolution of ligand-receptor pairs. Nature 1994 $368251-255$.

8 Hong S, Ji I \& Ji TH. The $\alpha$-subunit of human choriogonadotropin interacts with the exodomain of the luteinizing hormone/choriogonadotropin receptor. Endocrinology 1999140 2486-2493.

9 Sohn J, Ryu K, Siever G, Jeoung M, Ji I \& Ji TH. Follicle-stimulating hormone interacts with exoloop 3 of the receptor. Journal of Biological Chemistry 2002277 50165-50175.

10 Moyle WR, Ehrlich PH \& Canfield RE. Use of monoclonal antibodies to subunits of hCG to examine the orientation of the hormone in its complex with receptor. PNAS $1982792245-2249$.

11 Yoo J, Ji I \& Ji TH. Conversion of lysine 91 to methionine or glutamic acid in human choriogonadotropin $\alpha$ results in the loss of cAMP inducibility. Journal of Biological Chemistry 1991266 $17741-17743$.

12 Zeng H, Ji I \& Ji TH. Lys ${ }^{91}$ and His ${ }^{90}$ of the $\alpha$-subunit are crucial for receptor binding and hormone action of follicle-stimulating hormone (FSH) and play hormone-specific roles in FSH and human chorionic gonadotropin. Endocrinology $1995 \mathbf{1 3 6}$ 2948-2953.

13 Arnold CJ, Liu C, Lindau-Shepard B, Losavio ML, Patrascu MT \& Dias JA. The human follitropin $\alpha$-subunit $C$ terminus collaborates with a $\beta$-subunit cystine noose and an $\alpha$-subunit loop to assemble a receptor-binding domain competent for signal transduction. Biochemistry $1998371762-1768$.

14 Sherman GB, Wolfe MW, Farmerie TA, Clay C, Threadgill DS, Sharp DC \& Nilson JH. A single gene encodes the $\alpha$-subunits of the equine luteinizing hormone and chorionic gonadotropin. Molecular Endocrinology $19926951-959$.

15 Stewart F, Allen WR \& Moor RM. Influence of fetal genotype on the follicle-stimulating hormone/luteinizing hormone ratio of pregnant mare serum gonadotrophin. Journal of Endocrinology $197773419-425$.

16 Aggarwal BB, Farmer SW, Papkoff H, Stewart F \& Allen WR. Purification and characterization of donkey chorionic gonadotrophin. Journal of Endocrinology $1980 \mathbf{8 5} 449-455$.

17 Roser JF, Papkoff H, Murthy HMS, Chang YS, Chloupek RC \& Potes JAC. Chemical, biological and immunological properties of pituitary gonadotrophins from the donkey (Equus asinus); comparison with the horse (Equus caballus). Biology of Reproduction 198430 $1253-1262$.
18 Chopineau M, Martinat N, Troispoux C, Marichatou H, Combarnous Y, Stewart F \& Guillou F. Expression of horse and donkey LH in COS-7 cells: evidence for low FSH activity in donkey LH as compared with horse LH. Journal of Endocrinology $1997152371-377$.

19 Chopineau M, Martinat N, Marichatou H, Troispoux C, Auge-Gouillou C, Stewart F, Combarnous Y \& Guillou F. Evidence that the $\alpha$-subunit influences the specificity of receptor binding of the equine gonadotrophins. Journal of Endocrinology $1997 \mathbf{1 5 5}$ 241-245.

20 Chopineau M, Martinat N, Galet C, Guillou F \& Combarnous Y. $\beta$-subunit $102-104$ residues are crucial to confer FSH activity to equine LH/CG but are not sufficient to confer FSH activity to human CG. Journal of Endocrinology 2001169 55-63.

21 Chopineau M \& Stewart F. Cloning and analysis of the cDNA for the common $\alpha$-subunit of the donkey pituitary glycoprotein hormones. Journal of Molecular Endocrinology $1996 \mathbf{1 6}$ 9-13.

22 Saneyoshi T, Min K-S, Ma XJ, Nambo Y, Hiyama T, Tanaka S et al. Equine follicle-stimulating hormone: molecular cloning of $\beta$-subunit and biological role of the asparagine-linked oligosaccharide at asparagine of $\alpha$-subunit. Biology of Reproduction 200165 1686-1690.

23 Guillou F, Martinat N \& Combarnous Y. Rapid in vitro desensitization of the testosterone response in rat Leydig cells by sub-active concentration of porcine luteinizing hormone. FEBS Letters 1985 $1846-9$.

24 Sali A \& Blundell TL. Comparative protein modelling by satisfaction of spatial restraints. Journal of Molecular Biology 1993234 $779-815$.

25 Shao K, Purohit S \& Bahl OP. Effect of modification of all loop regions in the $\alpha$ - and $\beta$-subunits of human choriogonadotropin on its signal transduction activity. Molecular and Cellular Endocrinology $1996 \mathbf{1 2 2} 173-182$.

26 Shao K \& Bahl OP. Effect of modification of the $\beta$-hairpin and long loops simultaneously in both $\alpha$ - and $\beta$-subunits on the function of human choriogonadotropin: part II. Molecular and Cellular Endocrinology $1997127179-187$.

27 Myers RV, Wang Y \& Moyle WR. The surface of $\alpha$-subunit loop 1 distant from the subunit interface is exposed in the hCG lutropin receptor complex. Biochimica et Biophysica Acta $2000 \mathbf{1 4 7 5}$ 390-394.

28 Weiner RS \& Dias JA. Identification of assembled epitopes on the $\alpha$-subunit on human follicle stimulating hormone. Molecular and Cellular Endocrinology $19928541-52$.

29 Yoo J, Zeng H, Ji H, Murdoch WJ \& Ji TH. COOH-terminal amino acids of the $\alpha$ subunit play common and different roles in human choriogonadotropin and follitropin. Journal of Biological Chemistry $199326813034-13042$.

30 Chen F, Wang Y \& Puett D. The carboxy-terminal region of the glycoprotein hormone $\alpha$-subunit: contributions to receptor binding and signaling in human chorionic gonadotropin. Molecular Endocrinology $19926914-919$.

31 Ji I, Zeng H \& Ji TH. Receptor activation of and signal generation by the lutropin/choriogonadotropin receptor. Cooperation of $\mathrm{Asp}^{397}$ of the receptor and $\alpha \operatorname{Lys}^{91}$ of the hormone. Journal of Biological Chemistry $1993 \mathbf{2 6 8} 22971-22974$.

32 Marichatou H, Martinat N, Guillou F \& Combarnous Y. Human chorionic gonadotropin with C-elongated $\alpha$-subunit retains full receptor binding and partial agonist activity. European Journal of Endocrinology $2000142402-405$.

33 Remy JJ, Couture L, Pantel J, Haertlé T, Rabesona H, Bozon V, Pajot-Augy E, Robert P, Troalen F, Salesse R \& Bidart JM. Mapping of hCG-receptor complexes. Molecular and Cellular Endocrinology $199612579-91$.

Received 1 October 2003

Accepted 1 March 2004 